\title{
Improving reversible capacities of high-surface lithium insertion materials - the case of amorphous $\mathrm{TiO}_{2}$
}

\author{
Swapna Ganapathy ${ }^{1}$, Shibabrata Basak ${ }^{2}$, Anton Lefering ${ }^{1}$, Edith Rogers ${ }^{1}$, Henny W. Zandbergen ${ }^{2}$ and \\ Marnix Wagemaker ${ }^{1 *}$
}

Fundamental Aspects of Materials and Energy, Department of Radiation, Radionucleides and Reactors, Faculty of Applied Sciences, Delft University of Technology, Delft, Netherlands

${ }^{2}$ Kavli Institute of Nanoscience, Delft University of Technology, Delft, Netherlands

\section{Edited by:}

Jie Xiao, Pacific Northwest National

Laboratory, USA

\section{Reviewed by:}

Hui Xia, Nanjing University of Science and Technology, China

Ruigang Zhang, Toyota Research

Institute of North America, USA

\section{*Correspondence:}

Marnix Wagemaker, Fundamental

Aspects of Materials and Energy,

Department of Radiation,

Radionucleides and Reactors, Faculty

of Applied Sciences, Delft University

of Technology, Mekelweg 15, Delft

2629 JB, Netherlands

e-mail:m.wagemaker@tudelft.nl
Chemisorbed water and solvent molecules and their reactivity with components from the electrolyte in high-surface nano-structured electrodes remains a contributing factor toward capacity diminishment on cycling in lithium ion batteries due to the limit in maximum annealing temperature. Here, we report a marked improvement in the capacity retention of amorphous $\mathrm{TiO}_{2}$ by the choice of preparation solvent, control of annealing temperature, and the presence of surface functional groups. Careful heating of the amorphous $\mathrm{TiO}_{2}$ sample prepared in acetone under vacuum lead to complete removal of all molecular solvent and an improved capacity retention of $220 \mathrm{mAh} / \mathrm{g}$ over 50 cycles at a C/10 rate. Amorphous $\mathrm{TiO}_{2}$ when prepared in ethanol and heated under vacuum showed an even better capacity retention of $240 \mathrm{mAh} / \mathrm{g}$. From Fourier transform infra-red spectroscopy and electron energy loss spectroscopy measurements, the improved capacity is attributed to the complete removal of ethanol and the presence of very small fractions of residual functional groups coordinated to oxygen-deficient surface titanium sites. These displace the more reactive chemisorbed hydroxyl groups, limiting reaction with components from the electrolyte and possibly enhancing the integrity of the solid electrolyte interface. The present research provides a facile strategy to improve the capacity retention of nano-structured electrode materials.

Keywords: Li-ion battery, amorphous $\mathrm{TiO}_{2}$, nano-structured materials, surface functionalization, FTIR

\section{INTRODUCTION}

For approximately two decades graphite, allowing Li intercalation between the graphitic sheets, has been the dominant negative electrode for lithium ion batteries. Higher negative electrode capacities can be achieved by processes other than insertion/intercalation reactions including conversion/displacement and extrusion reactions (Poizot et al., 2000; Arico et al., 2005; Larcher et al., 2007; Armand and Tarascon, 2008; Bruce et al., 2008; Li et al., 2009; Scrosati and Garche, 2010; Szczech and Jin, 2011). Although these show much promise, generally the problems of large volume expansion limit the cycle life of these reaction mechanisms (Kasavajjula et al., 2007). The stable insertion reactions in transition metal oxides provide another richly studied alternative for graphite (Deng et al., 2009). One of the promising transition metal oxides is titanium dioxide $\mathrm{TiO}_{2}$, owing its popularity to its low cost, ease of preparation, and its high-theoretical capacity of $335 \mathrm{mAh} / \mathrm{g}$. Working around $1.5 \mathrm{~V}$ vs. $\mathrm{Li}^{2} / \mathrm{Li}^{+}$within the stability window of typical electrolytes results in inherent safety and stability of titanium oxides albeit with a loss in battery energy density due to the smaller working voltage (Yang et al., 2009; Kyeremateng et al., 2011; Plylahan et al., 2012; Wagemaker and Mulder, 2013). Among the most promising polymorphs are nanoparticles of $\mathrm{TiO}_{2}$-anatase (Sudant et al., 2005; Guo et al., 2007; Ren et al., 2010; Shin et al., 2011), nanowires and nanotubes of $\mathrm{TiO}_{2}$ (B) (Armstrong et al., 2005a; Zukalova et al., 2005), and the amorphous $\mathrm{TiO}_{2}$ (Borghols et al., 2010), but all of them suffer from an irreversible loss of capacity during the first battery cycles and a capacity retention that is lower than the theoretical maximum. This appears to be a drawback of nanosizing, for the irreversible capacity loss observed during the first few battery cycles is largely attributed to degradation of the electrolyte components at the electrode surface due to the presence of residual water or solvents. Recent attempts to diminish this initial capacity loss by using pre-lithiation to displace surface chemisorbed ${ }^{-} \mathrm{OH}$ groups by lithium appears to have been successful for $\mathrm{TiO}_{2}-(\mathrm{B})$ (Brutti et al., 2012) nanotubes, resulting in a more stable solid electrolyte interface (SEI) and better capacity retention, though applying this treatment on a larger scale may prove more challenging.

Amorphous $\mathrm{TiO}_{2}$ has been shown to possess a first discharge capacity that is about two and a half times higher than the theoretical maximum and a reversible capacity of $\sim 200 \mathrm{mAh} / \mathrm{g}$ at slow (dis)charge rates (Borghols et al., 2010). It appears very difficult to remove the surface adsorbed water and solvent molecules in this material as is the case for most high-surface titanium dioxides, whereas these residues are held responsible for the capacity fading observed during battery cycling (Morterra, 1988; Hadjiivanov and Klissurski, 1996; Diebold, 2003). In this study, we show that by the smart choice of preparation solvent and extended annealing at moderate temperatures under vacuum it is possible to (A) completely remove the preparation solvent or (B) to utilize 
this residual solvent to partially functionalize the surface eliminating some chemisorbed ${ }^{-} \mathrm{OH}$, and creating a more stable SEI thereby improving the capacity retention for amorphous $\mathrm{TiO}_{2}$. This provides a facile strategy to improve capacity retention of nano-structured electrode materials.

\section{MATERIALS AND METHODS SAMPLE PREPARATION}

The amorphous titania precursor was prepared by adding deionized water dropwise to a mixture of titanium isopropoxide and anhydrous acetone under stirring conditions in an ice bath (Livage et al., 1988; Sudant et al., 2005). The mixture was washed several times with anhydrous acetone after which it was pre-dried overnight at $50^{\circ} \mathrm{C}$. To prepare the nano-crystalline anatase $\mathrm{TiO}_{2}$ samples two heating schemes were used. The first sample hereafter referred to as ana- $\mathrm{TiO}_{2}-\mathrm{A}$, was prepared by heating the titania precursor with a heating ramp of room temperature to $250^{\circ} \mathrm{C}$ of $10 \mathrm{~min}$ and was further annealed for $1 \mathrm{~h}$. The second sample was prepared by heating the precursor on a ramp of room temperature to $250^{\circ} \mathrm{C}$ of $96 \mathrm{~h}$ and was allowed to anneal for an additional $24 \mathrm{~h}$ after reaching the set temperature. This sample shall be referred to from this point onward as sample ana- $\mathrm{TiO}_{2}-\mathrm{B}$. A part of each of these samples was dried further under vacuum at $80^{\circ} \mathrm{C}$ for a week to obtain vacuum dried anatase $\mathrm{TiO}_{2}$ samples that we shall label ana- $\mathrm{TiO}_{2}-\mathrm{C}$ and ana- $\mathrm{TiO}_{2}-\mathrm{D}$, respectively. The amorphous $\mathrm{TiO}_{2}$ samples were prepared by heating the pre-dried titania precursor in a vacuum tube oven set to 80,100 , and $130^{\circ} \mathrm{C}$, respectively, for 4 days for the first sample, 8 days for the second, and 15 days for the third. These samples shall be hereafter referred to as $\mathrm{A}-\mathrm{TiO}_{2}$ $80, \mathrm{~A}-\mathrm{TiO}_{2}-100$, and $\mathrm{A}-\mathrm{TiO}_{2}-130$. An additional set of amorphous $\mathrm{TiO}_{2}$ samples was made by using a titania precursor prepared in ethanol described by Borghols et al. (2010). The titania precursor was once again heated as described earlier to three different temperatures under vacuum for the same time duration and the amorphous samples so obtained shall be referred to as $\mathrm{E}-\mathrm{TiO}_{2}-80$, E-TiO $2-100$, and $\mathrm{E}-\mathrm{TiO}_{2}-130$.

\section{XRD MEASUREMENTS}

To characterize the nano-crystalline anatase $\mathrm{TiO}_{2}$ samples and to attain an initial estimate of particle sizes and to check whether the amorphous $\mathrm{TiO}_{2}$ samples remained amorphous through the heating, X-ray diffraction measurements were performed (supporting information). A PANalytical X'Pert Pro PW3040/60 diffractometer with $\mathrm{Cu} \mathrm{K}_{\alpha}$ radiation operating at $45 \mathrm{kV}$ and $40 \mathrm{~mA}$ in an angular $2 \theta$ range of $20-70^{\circ}$ was utilized.

\section{TEM MEASUREMENTS}

For preparing the TEM samples, the A-TiO2 and E- $\mathrm{TiO}_{2}$ samples were ultrasonicated in acetone or ethanol, respectively, for $30 \mathrm{~min}$ before dispersing them on standard TEM Cu-grids. TEM measurements were carried out in a FEI TECNAI microscope operating at $200 \mathrm{kV}$ with a Wien filter monochromator and equipped with an improved high-tension tank and a high-resolution GIF (HR-GIF). Electron energy loss spectroscopy measurements (EELS) measurements were done at a total energy resolution of $0.5 \mathrm{eV}$, determined by measuring the full width at half maximum of the zero-loss peak and an energy dispersion of $0.2 \mathrm{eV} /$ channel.

\section{ELECTROCHEMISTRY}

To test the various $\mathrm{TiO}_{2}$ samples in batteries, electrodes were formulated by mixing each $\mathrm{TiO}_{2}$ preparation with a binder (Kynar Flex) and carbon black (Super P) in a ratio of 70:20:10 by weight along with a solvent (NMP) and the mixture was subsequently cast on carbon coated aluminum foil using a doctor blade. The aluminum foil acted as a current collector. Circular pieces measuring $11 \mathrm{~mm}$ in diameter were cut out, compressed and then used in a battery, with lithium metal as the counter and reference electrode. The electrolyte was a $1 \mathrm{M}$ solution of $\mathrm{LiPF}_{6}$ in a EC:DMC (1:1) solvent. Electrochemical (dis)charge tests were performed with a MACCOR 5300 battery cycler.

\section{FTIR MEASUREMENTS}

Diffuse reflectance measurements were carried out in the near to mid infrared between 800 and $8000 \mathrm{~cm}^{-1}$. Measurements were obtained using a Pike Easydiff diffuse reflectance accessory in a Bruker Vertex $80 \mathrm{~V}$ Fourier transform infrared spectrometer using a Globar source, $\mathrm{KBr}$ beamsplitter, and a Ln-MCT detector (Kolmar Technologies KV 100-1-B7/190). KBr powder was used as a reference material as it is considered to have a good transmittance in this region.

\section{RESULTS AND DISCUSSION}

Rietveld refinement was performed on the diffraction patterns obtained for the anatase $\mathrm{TiO}_{2}$ samples A-D using GSAS (Larson and Von Dreele, 2004) program, resulting in residuals $R_{\mathrm{wp}}$ of $<8 \%$. No major differences were observed between samples ana$\mathrm{TiO}_{2}-\mathrm{A}$ and $\mathrm{C}$ and samples ana- $\mathrm{TiO}_{2}-\mathrm{B}$ and $\mathrm{D}$. The observed and refined diffraction patterns for samples ana- $\mathrm{TiO}_{2}-\mathrm{C}$ and $\mathrm{D}$ have been illustrated in Figure 1. The average particle sizes deduced from the line widths of the fitted peaks employing the Scherrer formula were $\sim 6.2$ and $9.1 \mathrm{~nm}$, respectively, for ana- $\mathrm{TiO}_{2}-\mathrm{C}$ and $\mathrm{D}$, respectively. The broad diffraction reflections of the $\mathrm{TiO}_{2}$

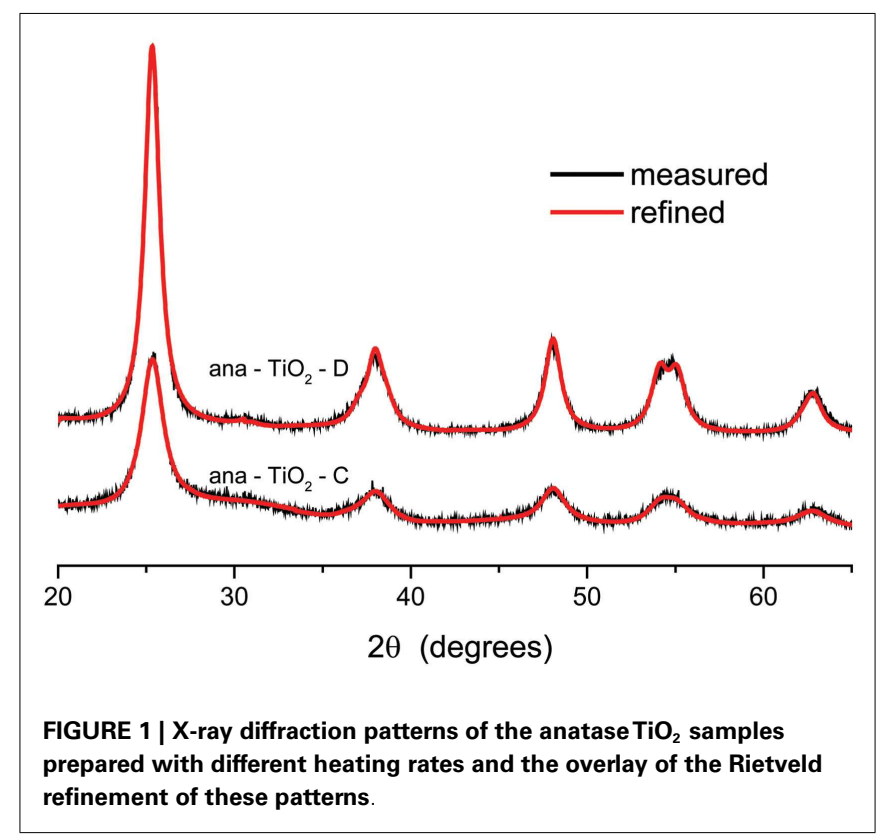


materials show that the materials are nano-crystalline with a considerable fraction amorphous material. The longer annealing time of the ana- $\mathrm{TiO}_{2}-\mathrm{D}$ material results in a larger crystalline fraction, and a larger crystallite size.

In order to determine the specific surface area of the $\mathrm{TiO}_{2}$ samples the Brunauer-Emmett-Teller (BET) method, $\mathrm{N}_{2}$ adsorption measurements were performed at $-195.85^{\circ} \mathrm{C}$. The average pore volume and pore size were determined from the absorptiondesorption isotherms measured using the Barrett-Joyner-Halenda (BJH) method, and the results for the amorphous $\mathrm{TiO}_{2}$ samples are listed in Table 1. The A- $\mathrm{TiO}_{2}-80$ sample has a BET surface area of $484 \mathrm{~m}^{2} / \mathrm{g}$ which is lower than that of the $\mathrm{E}-\mathrm{TiO}_{2}-80$ sample annealed at the same temperature, which has a specific surface area of $543 \mathrm{~m}^{2} / \mathrm{g}$. As is expected, the BET surface area decreased with an increase in annealing temperature. From the pore sizes calculated for $\mathrm{A}-\mathrm{TiO}_{2}$ and $\mathrm{E}-\mathrm{TiO}_{2}$, all samples fall into the category of mesoporous materials with pore sizes ranging from 3.5 to $3.8 \mathrm{~nm}$ for the $\mathrm{A}-\mathrm{TiO}_{2}$ samples and larger from 5.6 to $8.6 \mathrm{~nm}$ for the $\mathrm{E}-\mathrm{TiO}_{2}$ samples. The ana- $\mathrm{TiO}_{2}-\mathrm{C}$ and $-\mathrm{D}$ samples had BET surface areas of 222 and $130 \mathrm{~m}^{2} / \mathrm{g}$, respectively.

Further characterization was done using transmission electron microscopy where the high-resolution micrographs recorded for anatase samples ana- $\mathrm{TiO}_{2}-\mathrm{C}$ and ana- $\mathrm{TiO}_{2}-\mathrm{D}$ both resulted in average particle sizes between 5 and $10 \mathrm{~nm}$, respectively (supporting information). However, sample ana- $\mathrm{TiO}_{2}-\mathrm{D}$ had much more well-defined crystalline particles while the ana- $\mathrm{TiO}_{2}-\mathrm{C}$ sample appeared to be an amorphous/crystalline mix. The amorphous samples $\mathrm{A}-\mathrm{TiO}_{2}$ and $\mathrm{E}-\mathrm{TiO}_{2}$ resulted in average particle sizes between 2-3 and 3-5 nm, respectively. Representative micrographs for the $\mathrm{A}-\mathrm{TiO}_{2}-130$ and $\mathrm{E}-\mathrm{TiO}_{2}-130$ samples are shown in Figure 2. The observed particle sizes are in line with those calculated from the BET surface area. Additionally, the TEM micrographs at a lower magnification show that the aggregates of the E-TiO -130 particles are more porous compared to the $\mathrm{A}-\mathrm{TiO}_{2}-$ 130 particles, while on the other hand the $\mathrm{A}-\mathrm{TiO}_{2}-130$ particles form larger and extremely spherical aggregates. Very few fringes were observed in the HRTEM micrographs and electron diffraction indicated amorphous samples with a negligible crystalline fraction.

All $\mathrm{TiO}_{2}$ samples were (dis)charged galvanostatically (constant current) within a range of 2.5 and $0.8 \mathrm{~V}$ at a C/10 rate as shown in Figures 3 and 4 for the anatase and amorphous samples, respectively. The voltage plateau was observed at $\sim 1.75 \mathrm{~V}$ for all the anatase $\mathrm{TiO}_{2}$ samples, which corresponds to the existence of a welldefined two-phase region, and its truncated and sloping nature are characteristic of nano-crystalline electrode materials (Borghols et al., 2009). The samples ana- $\mathrm{TiO}_{2}-\mathrm{A}$ and ana- $\mathrm{TiO}_{2}-\mathrm{C}$ showed a higher first discharge capacities of 590 and $670 \mathrm{mAh} / \mathrm{g}$ (Figure 3A) compared to samples ana- $\mathrm{TiO}_{2}-\mathrm{B}$ and ana- $\mathrm{TiO}_{2}-\mathrm{D}$, which had first discharge capacities of 360 and $390 \mathrm{mAh} / \mathrm{g}$ (Figure 3A), respectively. These are remarkably high, though not unprecedented for nano-crystalline $\mathrm{TiO}_{2}$ materials (Armstrong et al., 2005a,b; Sudant et al., 2005; Borghols et al., 2008). The theoretical maximum capacity of $335 \mathrm{mAh} / \mathrm{g}$ is attained when a composition of $\mathrm{Li}_{1} \mathrm{TiO}_{2}$ is reached. The first discharge capacities obtained correspond to compositions of $\mathrm{Li}_{1.8} \mathrm{TiO}_{2}, \mathrm{Li}_{2} \mathrm{TiO}_{2}, \mathrm{Li}_{1.1} \mathrm{TiO}_{2}$, and

Table 1 | Variation in the BET surface area, pore volume, and pore size on heating the amorphous $\mathrm{TiO}_{2}$ samples prepared in acetone and ethanol at various temperatures under vacuum

\begin{tabular}{|c|c|c|c|c|c|}
\hline Sample & Temperature $\left({ }^{\circ} \mathrm{C}\right)$ & $\begin{array}{l}\text { BET surface } \\
\text { area }^{a}\left(\mathrm{~m}^{2} / \mathrm{g}\right)\end{array}$ & $\begin{array}{l}\text { Pore volume } \\
\qquad\left(\mathrm{cm}^{3} / \mathrm{g}\right)\end{array}$ & Pore size (nm) & $\begin{array}{c}\text { First discharge } \\
\text { capacity }(\mathrm{mAh} / \mathrm{g})\end{array}$ \\
\hline \multirow[t]{3}{*}{$\mathrm{A}-\mathrm{TiO}_{2}$} & 80 & 484 & 0.2291 & 3.8 & 360 \\
\hline & 100 & 460 & 0.2516 & 3.5 & 790 \\
\hline & 130 & 438 & 0.2107 & 3.7 & 860 \\
\hline \multirow[t]{3}{*}{$\mathrm{E}-\mathrm{TiO}_{2}$} & 80 & 543 & 0.0922 & 5.6 & 400 \\
\hline & 100 & 499 & 0.0887 & 5.8 & 800 \\
\hline & 130 & 409 & 0.0481 & 8.6 & 1170 \\
\hline
\end{tabular}

${ }^{a}$ Average particle size $=6000 /(B E T$ surface area $\times \rho)$, where $\rho=4.2 \mathrm{~g} / \mathrm{cm}^{3}$ for pure $\mathrm{TiO}_{2}$.
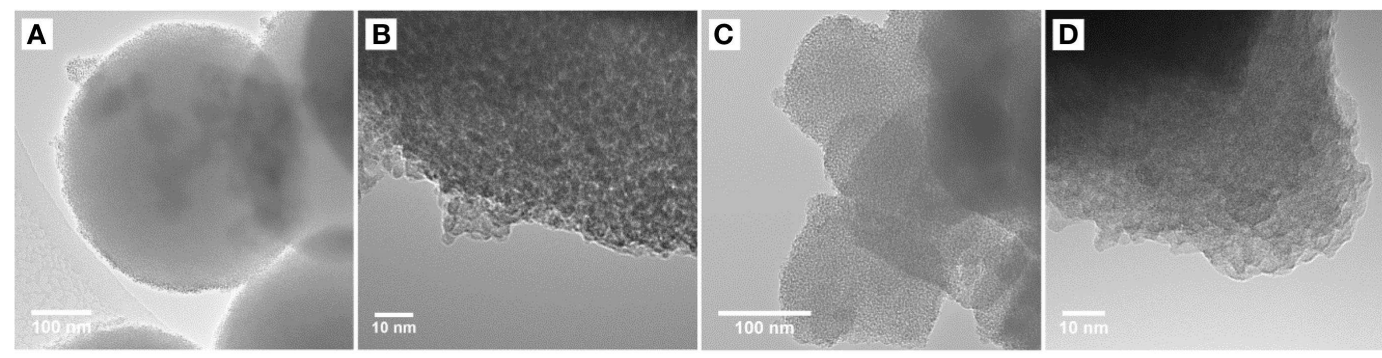

FIGURE 2 |TEM and HRTEM micrographs for amorphous $\mathrm{TiO}_{2}$ samples $(\mathrm{A}, \mathrm{B}) \mathrm{A}-\mathrm{TiO}_{2}-130$ and $(\mathrm{C}, \mathrm{D}) \mathrm{E}-\mathrm{TiO} \mathrm{C}_{2}-130$ 


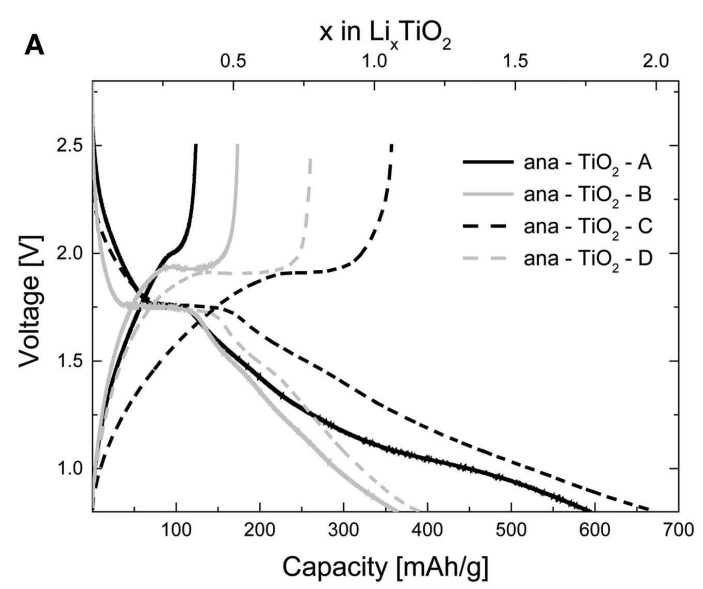

FIGURE 3 | (A) First cycle (dis)charge voltage profiles for the nano-crystalline anatase $\mathrm{TiO}_{2}$ samples measured in the galvanostatic mode at a C/10 rate. (B) Retention of capacity upon performing (dis)charge
B

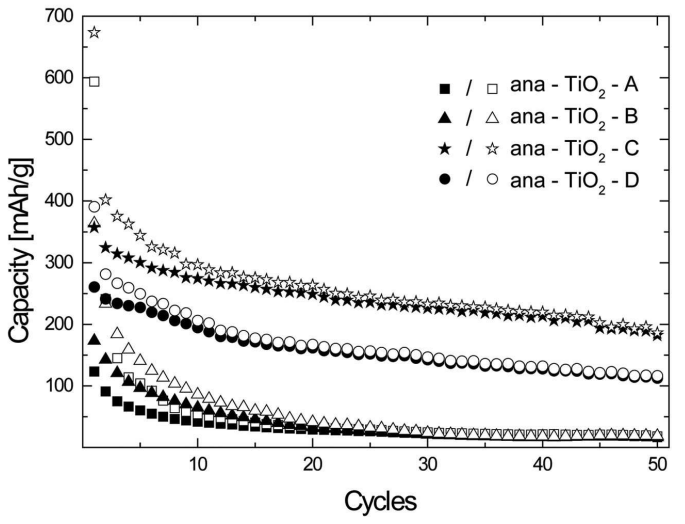

cycles at a $\mathrm{C} / 10$ rate for the nano-crystalline anatase $\mathrm{TiO}_{2}$ samples. The filled data points refer to the charge capacity while the hollow data points refer to the discharge capacity.

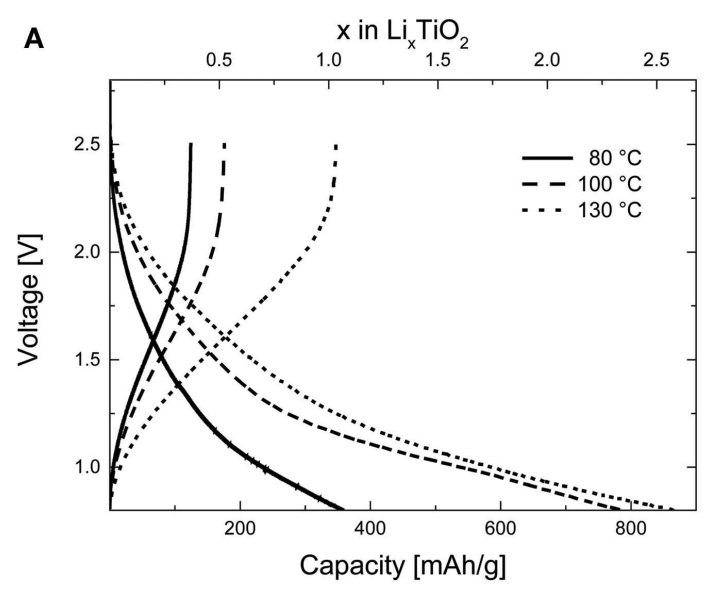

B

C
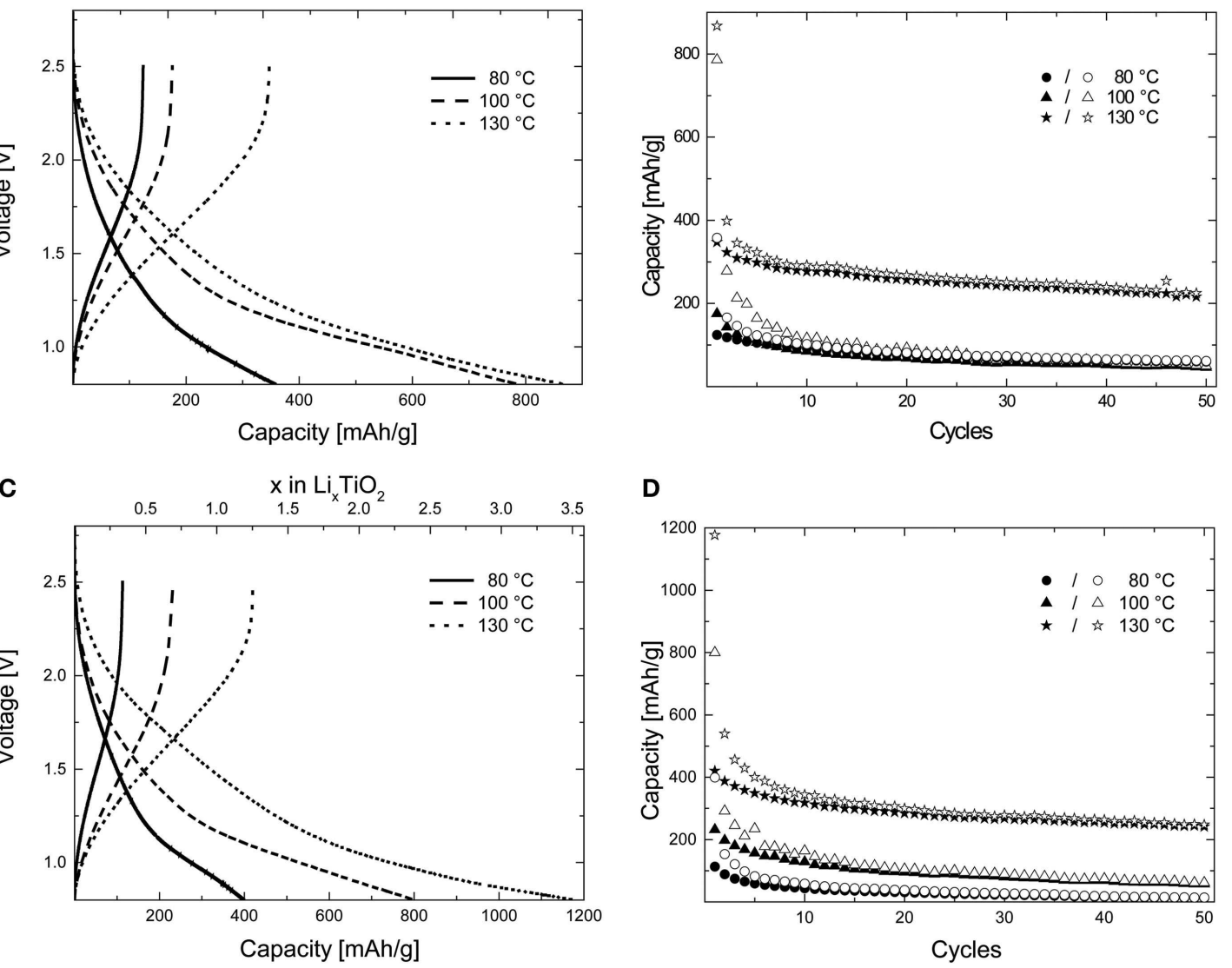

D

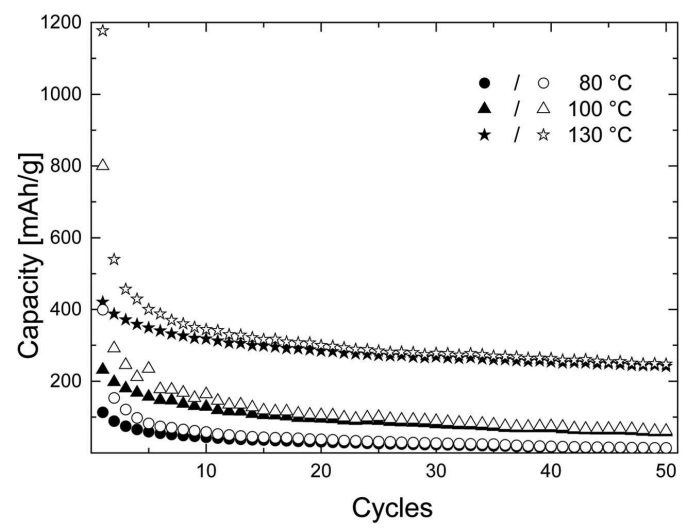

FIGURE 4 | (A,C) First cycle (dis)charge voltage profiles for the amorphous $\mathrm{TiO}_{2}$ samples prepared at various temperatures in ethanol and acetone, respectively, measured in the galvanostatic mode at a $\mathrm{C} / 10$ rate. (B,D) Retention of capacity upon performing (dis)charge cycles at a
$\mathrm{C} / 10$ rate for the amorphous anatase $\mathrm{TiO}_{2}$ samples prepared in ethanol and acetone at various temperatures. The filled data points refer to the charge capacity while the hollow data points refer to the discharge capacity. 
$\mathrm{Li}_{1.2} \mathrm{TiO}_{2}$ for samples ana-TiO $2-\mathrm{A}-\mathrm{D}$. The plateau corresponded to a composition of $\mathrm{Li}_{0.3-0.4} \mathrm{TiO}_{2}$ for samples ana-TiO${ }_{2}-\mathrm{A} /$ ana- $\mathrm{TiO}_{2}-\mathrm{B}$ and $\mathrm{Li}_{0.4-0.5} \mathrm{TiO}_{2}$ for samples ana- $\mathrm{TiO}_{2}-\mathrm{C} /$ ana- $\mathrm{TiO}_{2}-$ $\mathrm{D}$, respectively. On performing repeated battery (dis)charge cycles, however, a different picture arose. As seen in Figure 3B only samples ana- $\mathrm{TiO}_{2}-\mathrm{C}$ and ana- $\mathrm{TiO}_{2}-\mathrm{D}$, which were also additionally heated under vacuum show any substantial capacity retention at just under $200 \mathrm{mAh} / \mathrm{g}$ and just over $100 \mathrm{mAh} / \mathrm{g}$, respectively, after 50 battery cycles. The main difference between samples ana- $\mathrm{TiO}_{2}-\mathrm{C}$ and $-\mathrm{D}$ is the presence of the amorphous fraction, which arises due to the annealing conditions adopted during the preparation of sample ana- $\mathrm{TiO}_{2}-\mathrm{C}$. Lithium storage in the ana$\mathrm{TiO}_{2}-\mathrm{C}$ sample probably occurs via a combination of an insertion and capacitive mechanism occurring due to the presence of the high-surface amorphous component, leading to a higher overall capacity (Laskova et al., 2014). In the more crystalline ana- $\mathrm{TiO}_{2}-\mathrm{D}$ sample, the capacity is consistent what has been found for nano crystalline anatase particles (Sudant et al., 2005) in which case the storage takes place via lithium insertion. The maximum capacity has been shown to be strongly particle size dependent, in micron sized anatase being limited to $x \approx 0.5$ increasing up to the theoretical value $x=1$ when the particle size is reduced to $\sim 7 \mathrm{~nm}$ (Sudant et al., 2005; Wagemaker et al., 2007). This is a consequence of a second phase transition between $\mathrm{Li}_{0.5} \mathrm{TiO}_{2}$ and $\mathrm{Li}_{1} \mathrm{TiO}_{2}$ only occurring at the surface of the crystallites (Wagemaker et al., 2007).

For the amorphous samples prepared in different media and at different temperatures, a sloping voltage curve with no plateau is observed unlike what has been reported previously (Borghols et al., 2010) indicating a solid-solution or capacitive (Laskova et al., 2014) lithium insertion mechanism and the absence of a contributing crystalline anatase fraction (Wagemaker and Mulder, 2013). This is further corroborated by the HRTEM micrographs of the samples described in the preceding section by the absence of significant fringes. The samples $\mathrm{A}-\mathrm{TiO}_{2}-130$ and $\mathrm{E}-\mathrm{TiO}_{2}-130$ both showed extremely high-specific capacities after the first discharge to $0.8 \mathrm{~V}$ with 860 and $1170 \mathrm{mAh} / \mathrm{g}$ (Figures $4 \mathrm{~A}, \mathrm{C}$ ), respectively, both of which are unprecedented for the amorphous $\mathrm{TiO}_{2}$ polymorph (Borghols et al., 2010). These correspond to compositions of $\mathrm{Li}_{2.6} \mathrm{TiO}_{2}$ and $\mathrm{Li}_{3.5} \mathrm{TiO}_{2}$, respectively. The theoretical maximum capacity of $335 \mathrm{mAh} / \mathrm{g}$ is attained when a composition of $\mathrm{Li}_{1} \mathrm{TiO}_{2}$ is reached fully utilizing the $\mathrm{Ti}^{4+} / \mathrm{Ti}^{3+}$ redox couple. Interestingly, samples annealed at $100^{\circ} \mathrm{C}$ under vacuum also show high-specific capacities after the first discharge at 790 and $800 \mathrm{mAh} / \mathrm{g}$ (Figures 4A,C) for samples A-TiO $2-100$ and $\mathrm{E}-\mathrm{TiO}_{2}$ 100 , which is comparable to what has been reported previously in literature for amorphous $\mathrm{TiO}_{2}$. This corresponds to a composition of $\sim \mathrm{Li}_{2.4} \mathrm{TiO}_{2}$; however, the capacity fading is significant to $80 \mathrm{mAh} / \mathrm{g}$ after 50 cycles. Finally, samples annealed to $80^{\circ} \mathrm{C}$ result in first discharge capacities of 360 and 400 (Figures 4A,C) mAh/g significantly lower than those measured for samples annealed at higher temperatures. On performing multiple (dis)charge cycles only samples $\mathrm{A}-\mathrm{TiO}_{2}-130$ and $\mathrm{E}-\mathrm{TiO}_{2}-130$ show an appreciable capacity retention of 220 and $240 \mathrm{mAh} / \mathrm{g}$ after 50 battery cycles, the latter being the highest observed for pristine amorphous $\mathrm{TiO}_{2}$, though $\mathrm{C}-\mathrm{N}$ doped amorphous $\mathrm{TiO}_{2}$ samples, albeit having a lower BET surface area have been shown to produce higher reversible capacities (Borghols et al., 2010; Xiao et al., 2014).
To obtain better understanding of the increased capacity retention observed for the amorphous samples $\mathrm{A}-\mathrm{TiO}_{2}-130$ and $\mathrm{E}-$ $\mathrm{TiO}_{2}-130$ and the differences in capacity based only on altered sample preparation medium, Fourier transform infra-red (FTIR) spectroscopy measurements were performed on all the amorphous samples, resulting in the spectra depicted in Figure 5. For the samples prepared in acetone (Figure $5 \mathbf{A}$ ), each spectrum shows a broad absorption peak corresponding to an ${ }^{-} \mathrm{OH}$ stretching vibration of hydrogen bonded water molecules between 2500 and $3700 \mathrm{~cm}^{-1}$ $\left(3300 \mathrm{~cm}^{-1}\right)$, a peak corresponding to chemisorbed surface ${ }^{-} \mathrm{OH}$ groups at $3671 \mathrm{~cm}^{-1}$ and a peak at $1626 \mathrm{~cm}^{-1}$ corresponding to a $\mathrm{H}_{2} \mathrm{O}$ bending vibration. Despite heating to $130^{\circ} \mathrm{C}$ under vacuum for several hours the peaks corresponding to molecular water persists. The gradual diminishing in intensity and subsequent disappearance of peaks in the region of $3000-2800 \mathrm{~cm}^{-1}$ which belong to the $\mathrm{C}-\mathrm{H}$ functionality indicate that heating the sample to $130^{\circ} \mathrm{C}$ is sufficient to remove all remnants of acetone from the amorphous $\mathrm{TiO}_{2}$ material.

For the samples prepared in ethanol (Figure 5B) similar water peaks at $3671 \mathrm{~cm}^{-1}$ and in the region $2500-3700 \mathrm{~cm}^{-1}$ are observed. The $\mathrm{H}_{2} \mathrm{O}$ bending peak was present at $1626 \mathrm{~cm}^{-1}$ for the

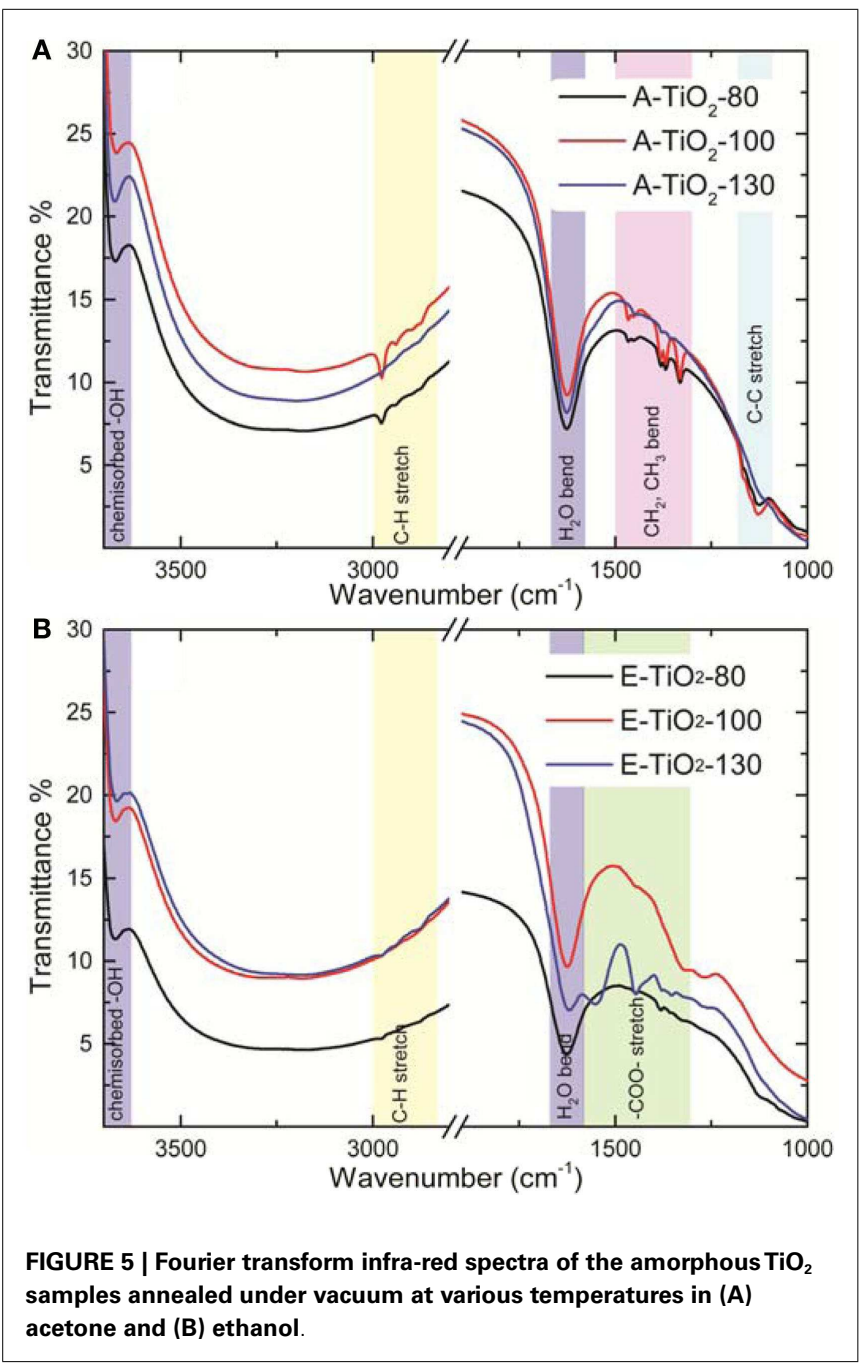


E-TiO -80 sample and shifted to $1622 \mathrm{~cm}^{-1}$ for the $\mathrm{E}-\mathrm{TiO}_{2}-100$ and $\mathrm{E}-\mathrm{TiO}_{2}-130$ samples. The characteristic peaks of ethanol physically adsorbed on a $\mathrm{TiO}_{2}$ surface at $1000-1200 \mathrm{~cm}^{-1}(\mathrm{C}-\mathrm{O}$ and $\mathrm{C}-\mathrm{C}$ stretching) and $1300-1500 \mathrm{~cm}^{-1}\left(\mathrm{CH}_{2}\right.$ and $\mathrm{CH}_{3}$ bending) are of extremely low intensity while the $\mathrm{O}-\mathrm{H}$ bending peak that should have appeared at $\sim 1264 \mathrm{~cm}^{-1}$ is absent in the $\mathrm{E}^{-\mathrm{TiO}_{2}-80 \text { samples }}$ (Hussein et al., 1991; Wu et al., 2000). This indicates that there is very little or no physically adsorbed ethanol remaining on a sample heated to $80^{\circ} \mathrm{C}$ under vacuum. The remaining peaks are attributed to co-adsorbed chemisorbed ethanol and $\mathrm{H}_{2} \mathrm{O}$ (Wu et al., 2000). Weak peaks at 2978,2938 , and $2977 \mathrm{~cm}^{-1}$ can be attributed to $\mathrm{CH}-$ stretching frequencies of chemisorbed ethoxide ions (Jackson and Parfitt, 1972; Graham et al., 1981). In the $\mathrm{E}-\mathrm{TiO}_{2}-130$ sample, new peaks centered at 1378,1446 , and $1547 \mathrm{~cm}^{-1}$ are observed, which are attributed to surface carboxylate $\left(\mathrm{COO}^{-}\right)$functionality (Graham et al., 1981; Hussein et al., 1991; Wu et al., 2000). This indicates that the chemisorbed ethanol species undergoes oxidation to form a carboxylate containing species, possibly acetate on heating above $100^{\circ} \mathrm{C}$ under vacuum. This is plausible because $\mathrm{TiO}_{2}$ in the presence of surface $\mathrm{OH}^{-}$groups is known to possess surface acid sites, the number and strength of which increases with decrease in crystallite size which in turn catalyzes the oxidation reaction (Nakabayashi et al., 1991). In addition nano-structured $\mathrm{TiO}_{2}$ when heated under vacuum, leads to the formation of oxygen-deficient species (Bavykin et al., 2006) $\left(\mathrm{Ti}_{4} \mathrm{O}_{7}\right.$ or $\left.\mathrm{Ti}_{5} \mathrm{O}_{9}\right)$ due to the removal of lattice oxygen atoms which also results in the presence of undercoordinated titanium sites at the surface, which has already been described in detail elsewhere (Borghols et al., 2010).

The low-columbic efficiency often displayed by high-surface $\mathrm{TiO}_{2}$ materials is typically ascribed to SEI (Bresser et al., 2012), the formation of which can only be prevented above $1.2 \mathrm{Vvs}$. $\mathrm{Li} / \mathrm{Li}^{+}$as been shown for high-surface anatase $\mathrm{TiO}_{2}$ nanorods (Bresser et al., 2012). This indicates that the SEI will be formed under the present conditions, galvanostatic cycling with a lower cut-off voltage of $0.8 \mathrm{~V}$ vs. $\mathrm{Li} / \mathrm{Li}^{+}$. In addition to the increase observed in capacity retention, there is also an increase in the irreversible discharge capacity compared to what has been reported previously for this material (Table 1) (Borghols et al., 2010; Xiao et al., 2014). Rather than scaling with the BET surface area, the first cycle capacity scales with the annealing temperature (Table 1). This indicates that the substantial irreversible capacity observed after the first discharge is a direct consequence of the solvent-free surfaces of the $\mathrm{A} / \mathrm{E}-\mathrm{TiO}_{2}$ 130 materials. The presence of more reactive surface titanium sites and residual $\mathrm{COO}^{-}$functional groups as determined from the IR measurements leads to a larger fraction of lithium being incorporated into the SEI possibly in the form of carbonate species. We suggest that the better capacity retention of samples annealed at higher temperatures is therefore due to a more stable SEI, which is the consequence of the absence of residual solvent molecules, unlike for samples annealed at 80 or $100^{\circ} \mathrm{C}$, where lithium continues to react with reactive solvent species leading to a much lower capacity retention.

To get a better indication of the amount of carbon in the E-TiO $2-130$ material, we also performed EELS focusing on the carbon K-edge, which is visible at $284 \mathrm{eV}$ as shown in Figure 6. For comparison purposes, the raw data are normalized to the maximum intensity. A carbon K-edge of appreciable intensity

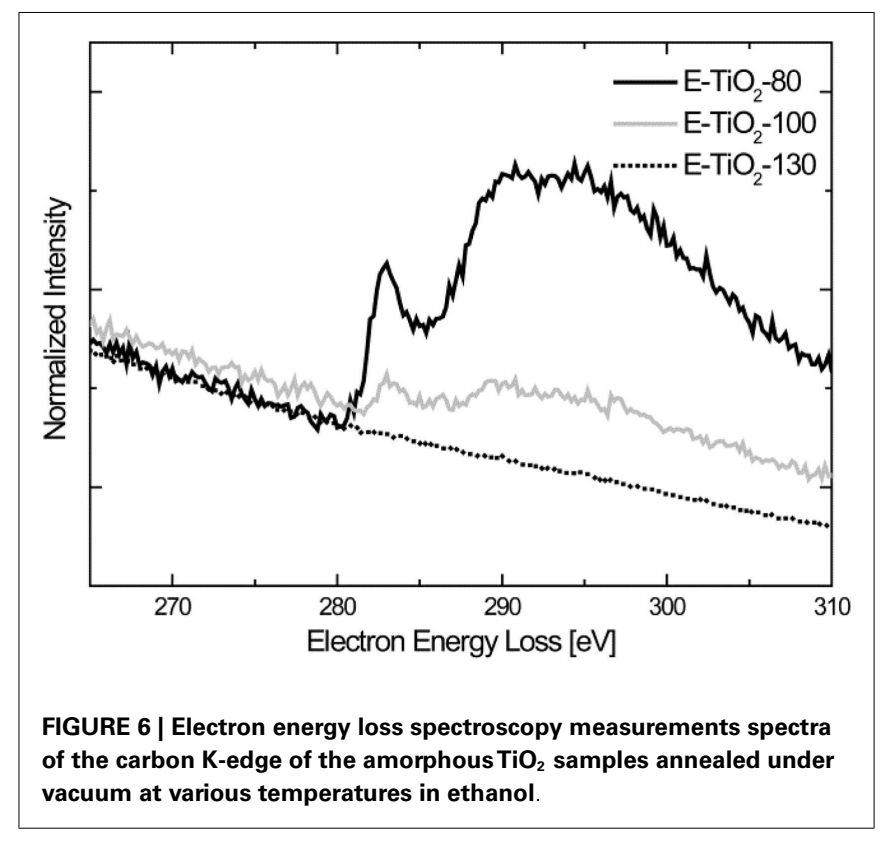

is observed for the $\mathrm{E}-\mathrm{TiO}_{2}-80$ sample and the intensity of the peak diminishes for the $\mathrm{E}-\mathrm{TiO}_{2}-100$ sample and no peak appears for the $\mathrm{E}-\mathrm{TiO}_{2}-130$ material. This reiterates the absence of any molecular ethanol and also indicates that the amount of surface carboxylate present is very small and only visible in the bulk FTIR measurements.

Amorphous $\mathrm{TiO}_{2}$ cannot be heated to higher temperatures without inducing crystallization. Nano-structured $\mathrm{TiO}_{2}$ has an inherent affinity to $\mathrm{H}_{2} \mathrm{O}$ and $\mathrm{OH}^{-}$groups, which persist despite heating to higher temperatures. The reactivity of these with the components of the electrolyte remains the main reason for capacity fading observed in these materials (Morterra, 1988). The consequence of the improved capacity observed for sample $\mathrm{E}-\mathrm{TiO}_{2}-130$ could be partially due to the presence of ester-like linkages of $\mathrm{RCOO}^{-}$groups to under-coordinated surface Ti sites (Figure 3). These potentially act as lithium carriers, improving Li-access and diffusion to all parts of the electrode during (dis)charge. A more stable bridging coordination of the $\mathrm{RCOO}^{-}$species to neighboring fourfold coordinated surface titanium atoms (Figure 5) (Diebold, 2003), may also be responsible for reducing the availability of titanium sites vulnerable to the attachment of surface hydroxyl groups. This is seen in the reduced intensity in the peak at $3671 \mathrm{~cm}^{-1}$ from the $\mathrm{E}-\mathrm{TiO}_{2}-80$ to $\mathrm{E}-\mathrm{TiO}_{2}-130$ samples. A consequence could be the reduced hydrolysis of $\mathrm{PF}_{6}^{-}$present in the electrolyte and subsequently smaller amounts of $\mathrm{LiF}$ and organophosphates formed implying a more stable SEI and hence better retention of capacity (Brutti et al., 2012).

\section{CONCLUSION}

To conclude, it has been shown that extended annealing under vacuum leads to capacity retention of 220 and $240 \mathrm{mAh} / \mathrm{g}$ after 50 cycles for amorphous $\mathrm{TiO}_{2}$ prepared in acetone and ethanol, respectively. Using FTIR and EELS, it was determined that for the amorphous $\mathrm{TiO}_{2}$ samples prepared in acetone, there is no residual solvent present, while for the samples prepared in ethanol the 


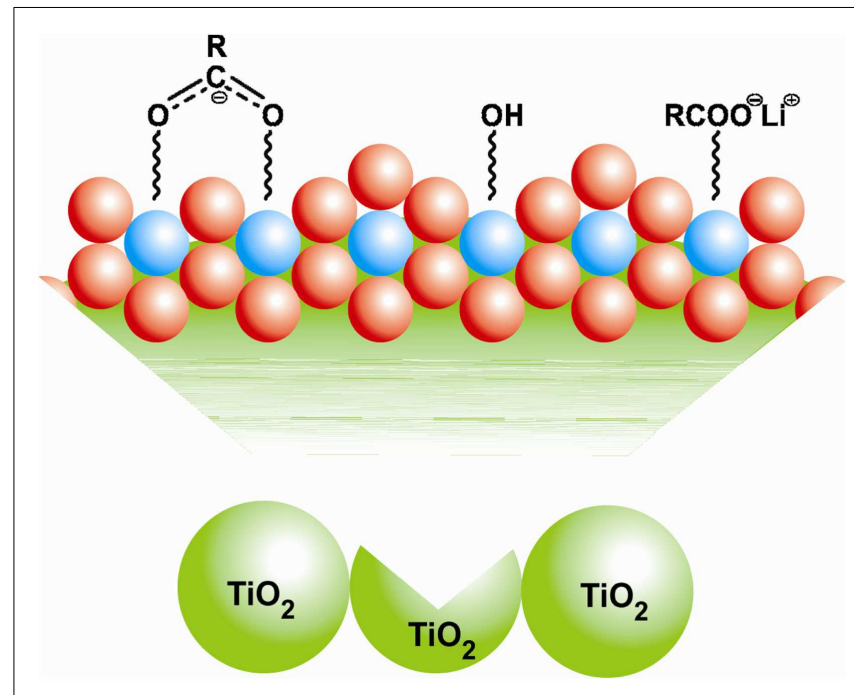

FIGURE 7 | Schematic for the various kinds of surface binding of the $\mathrm{COO}^{-}$and $\mathrm{OH}^{-}$groups at a section of the amorphous $\mathrm{TiO}_{2}$ particle surface. The blue and red spheres represent titanium and oxygen atoms, respectively.

surface of the amorphous $\mathrm{TiO}_{2}$ is partially functionalized by a small amount of residual functional groups coordinated to the oxygen-deficient surface displacing the more reactive hydroxyl groups. These results demonstrate even the presence of small amounts of residual solvent has a drastic impact on the electrochemistry of nano-structured battery electrodes due to their very large surface area and the simple act of extensive solvent cleaning from the sample allows the reversible capacity to be improved by up to $20 \%$. Thereby, the present results provide a simple and effective strategy to improve the performance of high-surface area transition metal oxides.

\section{ACKNOWLEDGMENTS}

We would like to thank Mr. David van Asten and BASF Nederland B.V. for their assistance with the $\mathrm{N}_{2}$ adsorption measurements. We would like to thank Mr. Prasad Gonugunta and Dr. Iulian Dugulan for their assistance with the FTIR measurements. We would also like to acknowledge financial support from NWO-NANO for Swapna Ganapathy and Shibabrata Basak. The research leading to these results has received funding from the European Research Council under the European Union's Seventh Framework Programme (FP/2007-2013)/ERC Grant Agreement no. (307161) of Marnix Wagemaker.

\section{SUPPLEMENTARY MATERIAL}

The Supplementary Material for this article can be found online at http://www.frontiersin.org/Journal/10.3389/fenrg.2014.00053/ abstract

\section{REFERENCES}

Arico, A. S., Bruce, P., Scrosati, B., Tarascon, J. M., and Van Schalkwijk, W. (2005). Nanostructured materials for advanced energy conversion and storage devices. Nat. Mater. 4, 366-377. doi:10.1038/nmat1368

Armand, M., and Tarascon, J. M. (2008). Building better batteries. Nature 451, 652-657. doi:10.1038/451652a
Armstrong, A. R., Armstrong, G., Canales, J., Garcia, R., and Bruce, P. G. (2005a). Lithium-ion intercalation into TiO2-B nanowires. Adv. Mater. 17, 862. doi:10. 1021/am4046487

Armstrong, A. R., Armstrong, G., Canales, J., and Bruce, P. G. (2005b). TiO2-B nanowires as negative electrodes for rechargeable lithium batteries. J. Power Sources 146, 501-506. doi:10.1016/j.jpowsour.2005.03.057

Bavykin, D. V., Friedrich, J. M., and Walsh, F. C. (2006). Protonated titanates and TiO2 nanostructured materials: Synthesis, properties, and applications. Adv. Mater. 18, 2807-2824. doi:10.1002/adma.200502696

Borghols, W. J. H., Luetzenkirchen-Hecht, D., Haake, U., Chan, W., Lafont, U., Kelder, E. M., et al. (2010). Lithium storage in amorphous $\mathrm{TiO} 2$ nanoparticles. J. Electrochem. Soc. 157, A582-A588. doi:10.1149/1.3332806

Borghols, W. J. H., Wagemaker, M., Lafont, U., Kelder, E. M., and Mulder, F. M. (2008). Impact of nanosizing on lithiated rutile TiO2. Chem. Mater. 20, 2949-2955. doi:10.1021/cm703376e

Borghols, W. J. H., Wagemaker, M., Lafont, U., Kelder, E. M., and Mulder, F. M. (2009). Size effects in the Li4+xTi5O12 spinel. J. Am. Chem. Soc. 131, 17786-17792. doi:10.1021/ja902423e

Bresser, D., Paillard, E., Binetti, E., Krueger, S., Striccoli, M., Winter, M., et al. (2012). Percolating networks of TiO 2 nanorods and carbon for high power lithium insertion electrodes. J. Power Sources 206, 301-309. doi:10.1016/j.jpowsour.2011. 12.051

Bruce, P. G., Scrosati, B., and Tarascon, J. M. (2008). Nanomaterials for rechargeable lithium batteries. Angew. Chem. Int. Ed. 47, 2930-2946. doi:10.1002/anie. 200702505

Brutti, S., Gentili, V., Menard, H., Scrosati, B., and Bruce, P. G. (2012). TiO2-(B) nanotubes as anodes for lithium batteries: origin and mitigation of irreversible capacity. Adv. Energy Mater. 2, 322-327. doi:10.1002/asia.201200551

Deng, D., Kim, M. G., Lee, J. Y., and Cho, J. (2009). Green energy storage materials: nanostructured $\mathrm{TiO} 2$ and Sn-based anodes for lithium-ion batteries. Energy Environ. Sci. 2, 818-837. doi:10.1039/b823474d

Diebold, U. (2003). The surface science of titanium dioxide. Surf. Sci. Rep. 48, 53-229. doi:10.1016/S0167-5729(02)00100-0

Graham, J., Rochester, C. H., and Rudham, R. (1981). Infrared study of the adsorption of ethyl-acetate on rutile. J. Chem. Soc. Faraday Trans. 1 77, 1973-1980. doi:10.1039/f19817701973

Guo, Y. G., Hu, Y. S., Sigle, W., and Maier, J. (2007). Superior electrode performance of nanostructured mesoporous $\mathrm{TiO} 2$ (anatase) through efficient hierarchical mixed conducting networks. Adv. Mater. 19, 2087. doi:10.1002/adma.200602828

Hadjiivanov, K. I., and Klissurski, D. G. (1996). Surface chemistry of titania (anatase) and titania-supported catalysts. Chem. Soc. Rev. 25, 61. doi:10.1039/ cs9962500061

Hussein, G. A. M., Sheppard, N., Zaki, M. I., and Fahim, R. B. (1991). Infrared spectroscopic studies of the reactions of alcohols over group IVb metaloxide catalysts.3. Ethanol over TIO2, ZRO2 and HFO2, and general conclusions from part-1 to part-3. J. Chem. Soc. Faraday Trans. 1 87, 2661-2668. doi: $10.1039 / \mathrm{ft} 9918702661$

Jackson, P., and Parfitt, G. D. (1972). Infrared study of surface properties of rutile adsorption of ethanol, butanol and hexanol. J. Chem. Soc. Faraday Trans. 1 68, 1443-1450. doi:10.1039/f19726801443

Kasavajjula, U., Wang, C., and Appleby, A. J. (2007). Nano- and bulk-siliconbased insertion anodes for lithium-ion secondary cells. J. Power Sources 163, 1003-1039. doi:10.1016/j.jpowsour.2006.09.084

Kyeremateng, N. A., Dumur, F., Knauth, P., Pecquenard, B., and Djenizian, T. (2011). Electropolymerization of copolymer electrolyte into titania nanotube electrodes for high-performance 3D microbatteries. Electrochem. Commun. 13, 894-897. doi:10.1186/1556-276X-7-349

Larcher, D., Beattie, S., Morcrette, M., Edström, K., Jumas, J. C., and Tarascon, J. M. (2007). Recent findings and prospects in the field of pure metals as negative electrodes for Li-ion batteries. J. Mater. Chem. 17, 3759-3772. doi:10.1039/b705421c

Larson, A. C., and Von Dreele, R. B. (2004). General Structure Analysis System (GSAS). Los Alamos: Los Alamos National Laboratory.

Laskova, B., Zukalova, M., Zukal, A., Bousa, M., and Kavan, L. (2014). Capacitive contribution to Li-storage in $\mathrm{TiO} 2$ (B) and TiO 2 (anatase). J. Power Sources 246, 103-109. doi:10.1016/j.jpowsour.2013.07.073

Li, H., Wang, Z., Chen, L., and Huang, X. (2009). Research on advanced materials for Li-ion batteries. Adv. Mater. 21, 4593-4607. doi:10.1002/adma.200901710

Livage, J., Henry, M., and Sanchez, C. (1988). Sol-gel chemistry of transition-metal oxides. Prog. Solid State Chem. 18, 259-341. doi:10.1016/0079-6786(88)90005-2 
Morterra, C. (1988). An infrared spectroscopic study of anatase properties. 6. Surface hydration and strong Lewis acidity of pure and sulfate-doped preparations. J. Chem. Soc. Faraday Trans. 1 84, 1617-1637. doi:10.1039/f19888401617

Nakabayashi, H., Kakuta, N., and Ueno, A. (1991). Strong acid sites created on smallsized anatase. Bull. Chem. Soc. Jpn. 64, 2428-2432. doi:10.1246/bcsj.64.2428

Plylahan, N., Kyeremateng, N. A., Eyraud, M., Dumur, F., Martinez, H., Santinacci, L., et al. (2012). Highly conformal electrodeposition of copolymer electrolytes into titania nanotubes for 3D li-ion batteries. Nanoscale Res. Lett. 7, 1-11. doi:10.1186/1556-276X-7-349

Poizot, P., Laruelle, S., Grugeon, S., Dupont, L., and Tarascon, J. M. (2000). Nanosized transition-metaloxides as negative-electrode materials for lithium-ion batteries. Nature 407, 496-499. doi:10.1038/35035045

Ren, Y., Hardwick, L. J., and Bruce, P. G. (2010). Lithium intercalation into mesoporous anatase with an ordered 3D pore structure. Angew. Chem. Int. Ed. 49, 2570-2574. doi:10.1002/anie.200907099

Scrosati, B., and Garche, J. (2010). Lithium batteries: Status, prospects and future. J. Power Sources 195, 2419-2430. doi:10.1002/adma.200903328

Shin, J. Y., Samuelis, D., and Maier, J. (2011). Sustained lithium-storage performance of hierarchical, nanoporous anatase TiO 2 at high rates: emphasis on interfacial storage phenomena. Adv. Funct. Mater. 21, 3464-3472. doi:10.1002/adfm. 201002527

Sudant, G., Baudrin, E., Larcher, D., and Tarascon, J. M. (2005). Electrochemical lithium reactivity with nanotextured anatase-type TiO2. J. Mater. Chem. 15, 1263-1269. doi:10.1039/b416176a

Szczech, J. R., and Jin, S. (2011). Nanostructured silicon for high capacity lithium battery anodes. Energy Environ. Sci. 4, 56-72. doi:10.1039/c0ee00281j

Wagemaker, M., Borghols, W. J. H., and Mulder, F. M. (2007). Large impact of particle size on insertion reactions: a case of anatase LixTiO2. J. Am. Chem. Soc. 129, 4323. doi:10.1021/ja067733p

Wagemaker, M., and Mulder, F. M. (2013). Properties and promises of nanosized insertion materials for li-ion batteries. Acc. Chem. Res. 46, 1206-1215. doi:10.1021/ar2001793
Wu, W. C., Chuang, C. C., and Lin, J. L. (2000). Bonding geometry and reactivity of methoxy and ethoxy groups adsorbed on powdered TiO2. J. Phys. Chem. B 104, 8719-8724. doi:10.1021/jp0017184

Xiao, Y., Hu, C., and Cao, M. (2014). Compositing amorphous TiO2 with N-doped carbon as high-rate anode materials for lithium-ion batteries. Chem. Asian J. 9, 351-356. doi:10.1002/asia.201301183

Yang, Z., Choi, D., Kerisit, S., Rosso, K. M., Wang, D., Zhang, J., et al. (2009). Nanostructures and lithium electrochemical reactivity of lithium titanites and titanium oxides: a review. J. Power Sources 192, 588-598. doi:10.1016/j.jpowsour. 2009.02.038

Zukalova, M., Kalbac, M., Kavan, L., Exnar, I., and Graetzel, M. (2005). Pseudocapacitive lithium storage in TiO2(B). Chem. Mater. 17, 1248-1255. doi:10.1021/ cm048249t

Conflict of Interest Statement: The authors declare that the research was conducted in the absence of any commercial or financial relationships that could be construed as a potential conflict of interest.

Received: 12 September 2014; accepted: 07 November 2014; published online: 28 November 2014.

Citation: Ganapathy S, Basak S, Lefering A, Rogers E, Zandbergen $H W$ and Wagemaker $M$ (2014) Improving reversible capacities of high-surface lithium insertion materials - the case of amorphous $\mathrm{TiO}_{2}$. Front. Energy Res. 2:53. doi: 10.3389/fenrg.2014.00053

This article was submitted to Energy Storage, a section of the journal Frontiers in Energy Research.

Copyright (C) 2014 Ganapathy, Basak, Lefering, Rogers, Zandbergen and Wagemaker. This is an open-access article distributed under the terms of the Creative Commons Attribution License (CC BY). The use, distribution or reproduction in other forums is permitted, provided the original author(s) or licensor are credited and that the original publication in this journal is cited, in accordance with accepted academic practice. No use, distribution or reproduction is permitted which does not comply with these terms. 